\title{
Optimal Control for the Transmission Dynamics of Tuberculosis
}

\author{
F. El kihal ${ }^{1}$, M. Al hia ${ }^{2}$ I. Abouelkheir ${ }^{3}$, M. Rachik ${ }^{4}$ \\ Laboratoire d'Analyse, Modélisation et Simulation (LAMS) June 16, 2016
}

\begin{abstract}
The subject of this work is the application of optimal control for the system of ordinary differential equation modeling a tuberculosis (TB) dis- ease with exogenous reinfection. A TB model that considers the existence of a new class (mainly in the african context) is considered: the lost to follow up individuals. Seeking to reduce the infections group by the re- duction of the contact between infections, lost and susceptible individuals, and to reduce the number of lost to follow up, we use control representing the prevention of exogenous reinfection. The Pontryagin's maximum prin- ciple is used to characterize the optimal control. An optimality system is derived and solved numerically.
\end{abstract}

Keywords: Optimal control, exogenous reinfection, Tuberculosis, TB model with exogenous reinfection

\section{Introduction}

Tuberculosis (TB) is an infectious disease caused by various strains of Mycobac- teria. Specially, Mycobacterium tuberculosis attacks the lungs and is spread through the air. Unique from other infectious diseases (e.g. infuenza, measles, etc), only a small portion of individuals develop active TB after primary infection. In fact, most individuals infected with TB remain in the latent stage and never become infectious or show symptoms of TB. In perspective, $30 \%$ of individuals in contact with active TB patients are infected (latent and active) while $10 \%$ of this infected group will become infectious (active). TB is the leading cause of death among infectious diseases with 2 billion infections and 3 million deaths in the world each year. Factors like age of infection and chronological age are important in TB progression because it is less likely for the development of active TB when the individual has carried the bacteria for

$$
\begin{aligned}
& \mathrm{dS}=\wedge-\mu \mathrm{S}-\beta(\mathrm{I}+\delta \mathrm{L}) \mathrm{S} \\
& \mathrm{dt} \\
& \mathrm{dE}=\beta \mathrm{p}_{2}(\mathrm{I}+\delta \mathrm{L}) \mathrm{S}+\overline{\gamma_{2}} \mathrm{~L}+\mathrm{r}_{2} \mathrm{I}-\left[\mu+\left(\mathrm{K}_{1}+\mathrm{K}_{2}\right)\left(1-\mathrm{r}_{1}\right)\right] \mathrm{E} \\
& \mathrm{dt} \\
& \mathrm{dI}=\beta \mathrm{p}_{1}(\mathrm{I}+\delta \mathrm{L}) \mathrm{S}+\mathrm{K}_{1}\left(1-\mathrm{r}_{1}\right) \mathrm{E}+\gamma_{1} \mathrm{~L}-\left[\mu+\mathrm{d}_{1}+\mathrm{r}_{2}+\Phi\left(1-\mathrm{r}_{2}\right)\right] \mathrm{I} \\
& \frac{\mathrm{dL}}{\mathrm{dt}}=\beta \mathrm{p}_{3}(\mathrm{I}+\delta \mathrm{L}) \mathrm{S}+\mathrm{K}_{2}\left(1-\mathrm{r}_{1}\right) \mathrm{E}+\left(1-\mathrm{r}_{2}\right) \mathrm{I}-\left[\mu+\mathrm{d}_{2}+\gamma_{1}+\gamma_{2}\right] \mathrm{L}
\end{aligned}
$$

We consider a population of $\mathrm{N}$ people. We assume that latently infected individuals (inactive TB) have a variable (typically long) latency period. At any given time, an individual is in one of the following four states: susceptible, latently infected (i.e., exposed to TB but are not infectious), infectious (i.e., has active TB but is in a care center), and lost to follow up (i.e., has active TB but is not in a care center).

We will denote these states by S; E; I; and L; respectively. Any recruitment is into the susceptible class and occurs at a constant rate $\wedge$. The transmission of tuberculosis occurs following an adequate contact between a susceptible and infectious or lost to follow up. We assume that a fraction $\delta$ of the lost to follow up are still a long time. Unfor- tunately, progression towards active TB may accelerate from repeated contact with active TB individuals [1].

According to the WHO [World Health Organisation (W HO), 2004] data published in April 2011 the TB case detection rate (all forms) in Cameroon was last reported at $69 \%$ in 2010 and the TB deaths reached 3,647 or $1.54 \%$ of total deaths. The age adjusted death rate of 21.89 per 100,000 of population ranks Cameroon 68th in the world [2].

In this article we present a tuberculosis model that incorporates the essential biological and epidemiological features of the disease such as exogenous reinfection and chemoprophylaxis of latently infected individuals, this model is governed by the following system of ordinary differential equations [3]

\section{Volume 5 Issue 7, July 2016}

\section{www.ijsr.net}




\section{International Journal of Science and Research (IJSR) \\ ISSN (Online): 2319-7064}

Index Copernicus Value (2013): 6.14 | Impact Factor (2015): 6.391

infectious class I to the latently infected class $\mathrm{E}$ at a rate $\mathbf{r}_{2}$. We assume that chemoprophylaxis of latently infected individuals reduces their reactivation at a constant rate $r_{2}$. We also assume that individuals leave the lost to follow up class $\mathrm{L}$ to the la- tently infected class E with a constant rate $\gamma_{2}$. This can be due to the response of the immune system or traditional treatment (via a traditional practitioner). Another assumption is that among the fraction $1-r_{2}$ of infectious who did not recover, some of them who had begun their treatment would not return to the hospital for the examination of sputum at a constant rate $\phi$ and enter the class of lost to follow up L. After some times, some of them will continue to suffer from the disease and will return to the hospital at a constant rate $\gamma_{1}$. We assume that the chemoprophylaxis of latently infected individuals E reduces their reactivation at rate $r 1$. Thus, a fraction $\left(1-r_{1}\right) E$ of infected individuals who do not receive effective chemoprophylaxis become infectious and lost to follow up with a constant rate $\mathrm{K}_{1}$ and $\mathrm{K}_{2}$, respectively (low progression of the disease). The constant rate for

$$
\begin{gathered}
\mathrm{dS}=\wedge-\mu \mathrm{S}-\beta(1-\mathrm{u})(\mathrm{I}+\delta \mathrm{L}) \mathrm{S} \\
\mathrm{dt}=\beta \mathrm{p}_{2}(1-\mathrm{u})(\mathrm{I}+\delta \mathrm{L}) \mathrm{S}+\gamma_{2} \mathrm{~L}+\mathrm{r}_{2} \mathrm{I}-\left[\mu+\left(\mathrm{K}_{1}+\mathrm{K}_{2}\right)\left(1-\mathrm{r}_{1}\right)\right] \mathrm{E} \\
\mathrm{dI}=\beta \mathrm{p}_{1}(1-\mathrm{u})(\mathrm{I}+\delta \mathrm{L}) \mathrm{S}+\mathrm{K}_{1}\left(1-\mathrm{r}_{1}\right) \mathrm{E}+\gamma_{1} \mathrm{~L}-\left[\mu+\mathrm{d}_{1}+\mathrm{r}_{2}+\Phi\left(1-\mathrm{r}_{2}\right)\right] \mathrm{I} \\
\left.\mathrm{dL}=\beta \mathrm{p}_{3}(1-\mathrm{u})(\mathrm{I}+\delta \mathrm{L}) \mathrm{S}+\mathrm{K}_{2}\left(1-\mathrm{r}_{1}\right) \mathrm{E}+\Phi 1-\mathrm{r}_{2}\right) \mathrm{I}-\left[\mu+\mathrm{d}_{2}+\gamma_{1}+\gamma_{2}\right] \mathrm{L}
\end{gathered}
$$

With initial condition $\mathrm{S}^{\mathrm{v}}(0)=\mathrm{S}_{0} ; \mathrm{E}(0)=\mathrm{E}_{0}$; $\mathrm{I}(0)=\mathrm{I}_{0}$;

$\lambda_{1}^{\prime}(\mathrm{t})=\lambda_{1} \mu+\left(\lambda_{1}-\lambda_{2} \mathrm{p}_{2}-\lambda_{3} \mathrm{p}_{1}-\lambda_{4} \mathrm{p}_{3}\right) \beta(1-\mathrm{u})$

$\mathrm{L}(0)=\mathrm{L}_{0}$

\section{The Optimal Control Problems}

The problem is to minimize the objective functional

$$
J(u)=\int_{t_{0}}^{t_{f}} L(t)+I(t)+A u^{2}(t) d t
$$

Where the parameter A represents the weight on the benefit and cost ( A balance the size of the terms). Our target is to minimize the objective functional defined in equation 3 by minimizing the number the infectious classes. In other words, we are seeking optimal control $u^{*}$ such that

$$
\mathbf{J}(\mathrm{u})=\min \{\mathrm{J}(\mathrm{u}): \mathrm{u} \in \mathrm{U}\}
$$
where $U$ is the control set defined by

$$
\mathrm{U}=\left\{\mathbf{u} \in \mathrm{L}^{1}\left(0, \mathrm{t}_{\mathrm{f}}\right): 0 \leq \mathrm{u} \leq 1\right\}
$$

Pontryagin's Maximum Principle [4], problems (2) (4) are reduced to mini- mize the function $\mathrm{H}$ defined by

$\mathrm{H}(\mathrm{u}, \mathrm{S}, \mathrm{E}, \mathrm{I}, \mathrm{L})=\mathrm{L}(\mathrm{t})+\mathrm{I}(\mathrm{t})+\mathrm{Au}^{2}(\mathrm{t})+\sum_{i=1}^{4} \lambda_{i} f_{i}$

where $f_{i}$ defined by the right-hand side of the system (2).

Theorem 1 There exists an optimal control $\mathrm{u}^{*}(\mathrm{t})$ and corresponding solution $\mathrm{S}^{*}, \mathrm{E}^{*}, \mathrm{I}^{*}, \mathrm{~T}^{*}$ and $\mathbf{J}^{*}$, taht minimize $\mathbf{J}(\mathrm{u})$ over $\mathrm{U}$. Furthermore, there ex is t s adjoint functions, $\lambda_{1}, \lambda_{2}, \lambda_{3}, \lambda_{4}$ satisfying the equations non-disease-related death is $\mu$, thus $\frac{1}{\mu}$ is the average lifetime. Infectious and lost to follow up have additional death rates due to TB-induced mortality with constant rates $d_{1}$ and $d_{2}$, respectively. We have $\mathrm{N}=\mathrm{S}+\mathrm{E}+\mathrm{I}+\mathrm{L}$ individuals; and $\beta$ the transmission rate.

\section{The Control and its Policy}

The subject of this control is to reduce the infections group by the reduction of the contact between infections and traited individuals, and to reduce the number of lost to follow up during a period of time $\mathbf{t}_{\mathrm{f}}$. We adopt a control parameter $\mathrm{u}(\mathrm{t})$, representing the following.

$\mathrm{u}=$ The effort made to reduce the contact between the infections and traited individuals.

Having introduced the functions $u(t)$; we obtain the following differential system:
$\left(\mathrm{I}^{*}+\delta \mathrm{L}^{*}\right)$

$\lambda_{2}^{\prime}(\mathrm{t})=\lambda_{2} \mu+\left(\lambda_{2}-\lambda_{3}\right) \mathrm{K}_{1}\left(1-\mathrm{r}_{1}\right)+\left(\lambda_{2}-\lambda_{4} \mathrm{~K}_{2}\left(1-\mathrm{r}_{1}\right)\right.$

$\lambda_{3}^{\prime}(\mathrm{t})=-1+\lambda_{3}\left(\mu+\mathrm{d}_{1}\right)+\left(\lambda_{1}-\lambda_{2} \mathrm{p}_{2}-\lambda_{3} \mathrm{p}_{1}-\lambda_{4} \mathrm{p}_{3}\right) \beta(1-$

$\mathrm{u}) \mathrm{S}^{*}+\left(\lambda_{3}-\lambda_{2}\right) \mathrm{r}_{2}+\left(\lambda_{3}-\lambda_{4}\right) \phi\left(1-\mathrm{r}_{2}\right)$

$\lambda_{4}^{\prime}(\mathrm{t})=-1+\lambda_{4}\left(\mu+\mathrm{d}_{2}\right)+\left(\lambda_{1}-\lambda_{2} \mathrm{p}_{2}-\lambda_{3} \mathrm{p}_{1}-\lambda_{4} \mathrm{p}_{3}\right) \beta(1-$

u) $\delta \mathrm{S}+\left(\lambda_{4}-\lambda_{2}\right) \gamma_{2}+\left(\lambda_{4}-\lambda_{3}\right) \gamma_{1}$

with transversality conditions

$$
\lambda_{\mathrm{i}}\left(\mathbf{t}_{\mathrm{f}}\right)=0 ; \mathrm{i}=1, \ldots, 4 .
$$

Moreover, the optimal control is given by

$$
u^{*}=\min \left(1, \max \left(0, \frac{1}{2 A}\left(\lambda_{2} p_{2}+\lambda_{3} p_{1}+\lambda_{4} p_{3}-\lambda_{1}\right) \beta\left(I^{*}+\right.\right.\right.
$$$$
\delta L * S *
$$

Proof Due to the convexity of integrand of $\mathbf{J}$ with respect to $\mathrm{u}$, a priori boundedness of the state solutions, and the Lipshitz property of the state system with respect to the state variables. The existence of an optimal control has been given by [5]. The adjoint equations and transversality conditions can be obtained by using Pontryagin's Maximum Principle such that

$$
\begin{aligned}
& \lambda_{1}^{\prime}=-\frac{\partial H}{\partial S}, \lambda_{1}\left(t_{f}\right)=0 \\
& \lambda_{2}^{\prime}=-\frac{\partial H}{\partial E}, \lambda_{2}\left(t_{f}\right)=0 \\
& \lambda_{3}^{\prime}=-\frac{\partial H}{\partial I}, \lambda_{3}\left(t_{f}\right)=0 \\
& \lambda_{4}^{\prime}=-\frac{\partial H}{\partial L}, \lambda_{4}\left(t_{f}\right)=0
\end{aligned}
$$




\section{International Journal of Science and Research (IJSR) \\ ISSN (Online): 2319-7064 \\ Index Copernicus Value (2013): 6.14 | Impact Factor (2015): 6.391}

The optimal control u can be solve from the optimality condition,

That is

$$
\frac{\partial H}{\partial u}=0
$$

$$
\begin{gathered}
\frac{\partial H}{\partial u}=2 A u+\left(\lambda_{1}-\lambda_{2} p_{2}-\lambda_{3} p_{1}-\lambda_{4} p_{3}\right) \beta\left(I^{*}+\delta L^{*}\right) S^{*} \\
=0
\end{gathered}
$$

By the bounds in $U$ of the controls, it is easy to obtain $\mathrm{u}^{*}$ in the form of 6

\section{Numerical Simulations}

$$
\begin{aligned}
& \frac{S_{i+1}-S_{i}}{h}=\wedge-\mu S_{i+1}-\beta\left(1-u_{i}\right)\left(I_{i}+\delta L_{i}\right) S_{i+1} \\
& \frac{E_{i+1}-E_{i}}{h}=\beta p_{2}\left(1-u_{i}\right)\left(I_{i}+\delta L_{i}\right) S_{i+1}+\gamma_{2} L_{i}+r_{2} I_{i}-\left[\mu+\left(K_{1}+K_{2}\right)\left(1-r_{1}\right)\right] E_{i+1} \\
& \frac{I_{i+1}-I_{i}}{h}=\beta p_{1}\left(1-u_{i}\right)\left(I_{i+1}+\delta L_{i}\right) S_{i+1}+K_{1}\left(1-r_{1}\right) E_{i+1}+\gamma_{1} L_{i}-\left[\mu+d_{1}+r_{2}+\phi\left(1-r_{2}\right)\right] I_{i+1} \\
& \frac{L_{i+1}-L_{i}}{h}=\beta p_{3}\left(1-u_{i}\right)\left(I_{i+1}+\delta L_{i+1}\right) S_{i+1}+K_{2}\left(1-r_{1}\right) E_{i+1}+\phi\left(1-r_{2}\right) I_{i+1}-\left[\mu+d_{2}+\gamma_{1}+\gamma_{2}\right] L_{i+1}
\end{aligned}
$$

The Method, developed by [6] and presented in [7], is then read as:
By using a similar technique, we approximate the time derivative of the adjoint variables by their firstorder backward-difference and we use the appropriated scheme as follows

$$
\begin{aligned}
\frac{\lambda_{1}^{n-i}-\lambda_{1}^{n-i-1}=}{h}= & \lambda_{1}^{n-i-1} \text { ? } \\
& +\left(\lambda_{1}^{n-i-1}-\lambda_{2}^{n-i} p_{2}-\lambda_{3}^{n-i} p_{1}\right. \\
& \left.-\lambda_{4}^{n-i} p_{3}\right) \beta\left(1-u_{i}\right)\left(I_{i+1}+\delta L_{i+1}\right) \\
\frac{\lambda_{2}^{n-i}-\lambda_{2}^{n-i-1}=}{h}= & \lambda_{2}^{n-i-1} \text { ? }+\left(\lambda_{2}^{n-i-1}-\lambda_{3}^{n-i}\right) K_{1}\left(1-r_{1}\right) \\
& +\left(\lambda_{2}^{n-i-1}-\lambda_{4}^{n-i}\right) K_{2}\left(1-r_{1}\right) \\
\frac{\lambda_{3}^{n-i}-\lambda_{3}^{n-i-1}=}{h} & -1+\lambda_{3}^{n-i-1}\left(\mu+d_{1}\right) \\
& +\left(\lambda_{1}^{n-i-1}-\lambda_{2}^{n-i-1} p_{2}-\lambda_{3}^{n-i-1} p_{1}\right. \\
& \left.-\lambda_{4}^{n-i} p_{3}\right) \beta\left(1-u_{i}\right) S_{i+1} \\
& +\left(\lambda_{3}^{n-i-1}-\lambda_{2}^{n-i-1}\right) r_{2} \\
& +\left(\lambda_{3}^{n-i-1}-\lambda_{4}^{n-i}\right) \phi\left(1-r_{2}\right) \\
\frac{\lambda_{4}^{n-i}-\lambda_{4}^{n-i-1}}{h}= & -1+\lambda_{4}^{n-i-1}\left(\mu+d_{2}\right) \\
& +\left(\lambda_{1}^{n-i-1}-\lambda_{2}^{n-i-1} p_{2}-\lambda_{3}^{n-i-1} p_{1}\right. \\
& \left.-\lambda_{4}^{n-i-1} p_{3}\right) \beta\left(1-u_{i}\right) \delta S_{i+1} \\
& +\left(\lambda_{4}^{n-i-1}-\lambda_{2}^{n-i-1}\right) \gamma_{2} \\
& +\left(\lambda_{4}^{n-i-1}-\lambda_{3}^{n-i-1}\right) \gamma_{1} \\
&
\end{aligned}
$$

The algorithm describing the approximation method for obtaining the optimal control is the following

\section{Algorithm}

Step 1:

$\mathrm{S}(0)=\mathrm{S}_{0} ; \mathrm{E}(0)=\mathrm{E}_{0} ; \mathrm{I}(0)=\mathrm{I}_{0} ; \mathrm{L}(0)=\mathrm{L}_{0} ; \lambda_{\mathrm{i}}\left(\mathrm{t}_{\mathrm{f}}\right)=$ $0(\mathrm{i}=1, \ldots, 4) ; \mathrm{u}(0)=0$.
Step 2: for $\mathrm{i}=1, \ldots, \mathrm{n}-1$, do :

$S_{i+1}=\frac{S_{i}+h \wedge}{1+h\left[0+\beta\left(1-u_{i}\right)\left(I_{i}+\delta L_{i}\right)\right]}$

$E_{i+1}=\frac{E_{i}+h\left[\beta p_{2}\left(1-u_{i}\right)\left(I_{i}+\delta L_{i}\right) S_{i+1}+\gamma_{2} L_{i}+r_{2} I_{i}\right]}{1+h\left[\mu+\left(K_{1}+K_{2}\right)\left(1-r_{1}\right)\right]}$

$I_{i+1}$

$=\frac{I_{i}+h\left[\beta p_{1}\left(1-u_{i}\right) \delta L_{i} S_{i+1}+K_{1}\left(1-r_{1}\right) E_{i+1}+\gamma_{1} L_{i}\right]}{1+h\left[\mu+d_{1}+r_{2}+\phi\left(1-r_{2}\right)-\beta p_{1}\left(1-u_{i}\right) S_{i+1}\right]}$

$L_{i+1}$

$=\frac{L_{i}+h\left[\beta p_{3}\left(1-u_{i}\right) I_{i+1} S_{i+1}+K_{2}\left(1-r_{1}\right) E_{i+1}+\phi(1-r\right.}{1+h\left[\mu+d_{2}+\gamma_{1}+\gamma_{2}-\beta p_{3}\left(1-u_{i}\right) \delta S_{i+1}\right]}$

$\lambda_{1}^{n-i-1}$ $=\frac{\lambda_{1}^{n-i}+h\left[\beta\left(1-u_{i}\right)\left(I_{i+1}+\delta L_{i+1}\right)\left(\lambda_{2}^{n-i} p_{2}-\lambda_{3}^{n-i} p_{1}-\lambda_{4}^{n-i}\right.\right.}{1+h\left[2+\beta\left(1-u_{i}\right)\left(I_{i+1}+\delta L_{i+1}\right)\right]}$

$1+h\left[0+\beta\left(1-u_{i}\right)\left(I_{i+1}+\delta L_{i+1}\right)\right]$

$\lambda_{2}^{n-i-1}=\frac{\lambda_{2}^{n-i}+h\left[\left(1-r_{1}\right)\left(\lambda_{3}^{n-i} K_{1}+\lambda_{4}^{n-i} K_{2}\right)\right]}{1+h\left[?+\left(K_{1}+K_{2}\right)\left(1-r_{1}\right)\right]}$

$\lambda_{3}^{n-i-1}$

$=\frac{\lambda_{3}^{n-i}+h\left[1+\beta\left(1-u_{i}\right) S_{i+1}\left(\lambda_{2}^{n-i-1} p_{2}+\lambda_{4}^{n-i} p_{3}-\lambda_{1}^{n-i-1}\right)\right.}{1+h\left[\mu+d_{1}+r_{2}+\phi\left(1-r_{2}\right)+\beta p_{2}(1\right.}$

$\lambda_{4}^{n-i-1}$

$=\frac{\lambda_{4}^{n-i}+h\left[1+\beta\left(1-u_{i}\right) \delta S_{i+1}\left(\lambda_{2}^{n-i-1} p_{2}+\lambda_{3}^{n-i-1} p_{1}-\lambda_{1}^{n-i}\right.\right.}{1+h\left[\mu+d_{2}+\gamma_{2}+\gamma_{1}+\beta p_{3}\left(1-u_{i}\right.\right.}$

$R_{i+1}=\frac{\left(\lambda_{1}-\lambda_{2} p_{2}-\lambda_{3} p_{1}-\lambda_{4} p_{3}\right) \beta\left(I^{*}+\delta L^{*}\right) S^{*}}{2 A}$

$u_{i+1}=\min \left(1, \max \left(R_{i+1}, 0\right)\right)$

\section{Step 3:}

for $\mathrm{i}=1, \ldots, \mathrm{n}-1$; write

$S^{*}\left(\mathrm{t}_{\mathrm{i}}\right)=\mathrm{S}_{\mathrm{i}}, E^{*}\left(\mathrm{t}_{\mathrm{i}}\right)=\mathrm{E}_{\mathrm{i}}, \mathrm{I}^{*}\left(\mathrm{t}_{\mathrm{i}}\right)=\mathrm{I}_{\mathrm{i},}, \mathrm{L}^{*}\left(\mathrm{t}_{\mathrm{i}}\right)=\mathrm{L}_{\mathrm{i}}, \mathrm{u}^{*}\left(\mathrm{t}_{\mathrm{i}}\right)$

$=\mathrm{u}_{\mathrm{i}}$ :

end for

\section{Volume 5 Issue 7, July 2016}

www.ijsr.net 


\section{International Journal of Science and Research (IJSR) \\ ISSN (Online): 2319-7064 \\ Index Copernicus Value (2013): 6.14 | Impact Factor (2015): 6.391}

The following parameters and initial values are used for the simulation which we have taken from [3],[8],[9] and [10] :

We assumed that $\beta$ is variable because it strongly influences the basic re-production ratio, we also assume that the parameters $\phi$ and $\mathrm{K}_{2}$, which denote the rate of progression from infectious to lost to follow up and the rate of pro- gression from latently infected to lost follow up, respectively, are variable just to highlight the fact that the optimal control depends on that parameters.

For numerical simulations the values of the above parameters $\quad$ are $\quad \beta \in\{0.002 ; 0.003 ; 0.02\}, \Phi \in$ $\{0.0022 ; 0.1 ; 0.5\}$, and $K_{2} \in\{0.0006 ; 0.006\}$. The values of the other parameters are given in Table 1 .

Table 1: Table of parameter values

\begin{tabular}{llcc}
\hline Parameters & Description & Estimated values & Source \\
\hline$\Lambda$ & Recruitment rate of susceptible individuals & $5(\mathrm{yr})^{-1}$ & Assumed \\
$\beta$ & Transmission rate & variable & Assumed \\
$\mu$ & Natural death rate & $0.019896(\mathrm{yr})^{-1}$ & {$[8]$} \\
$d_{1}$ & TB-induced mortality for the follow up & $0.02272(\mathrm{yr})^{-1}$ & {$[9]$} \\
$d_{2}$ & TB-induced mortality for the lost to follow up & $0.20(\mathrm{yr})^{-1}$ & {$[9]$} \\
$\delta$ & Fraction of lost to follow up that are still infectious & $1(\mathrm{yr})^{-1}$ & Assumed \\
$\phi$ & Rate at which infectious become lost to follow up & Variable & Assumed \\
$p_{1}$ & Fast route to infectious class & $0.3(\mathrm{yr})^{-1}$ & {$[9]$} \\
$p_{3}$ & Fast route to lost to follow up class & $0.1(\mathrm{yr})^{-1}$ & Assumed \\
$r_{1}$ & Chemoprophylaxis of latently infected individuals & $0.001(\mathrm{yr})^{-1}$ & {$[9]$} \\
$r_{2}$ & Recovery rate of the infectious & $0.7311(\mathrm{yr})^{-1}$ & {$[9]$} \\
$\gamma_{1}$ & Rate at which the lost to follow up return to the hospital & $0.2(\mathrm{yr})^{-1}$ & Assumed \\
$\gamma_{2}$ & Recovering rate for the lost to follow up & $0.001(\mathrm{yr})^{-1}$ & Assumed \\
$k_{1}$ & Rate of progression from infected latently to infectious & $0.0005(\mathrm{yr})^{-1}$ & {$[10]$} \\
$k_{2}$ & Rate of progression from infected latently to lost to follow up & Variable & Assumed \\
\hline
\end{tabular}

For those simulations, we take $\mathbf{t}_{\mathrm{f}}=5$ years as control period. We also assume that the total population number is $\mathrm{N}=500$ individuals subdivided as follows: $\mathrm{S}(0)=50$, $\mathrm{E}(0)=100, \mathrm{I}(0)=150$, and $\mathrm{L}(0)=200$.

The figures represents The influence of the control $u^{*}$

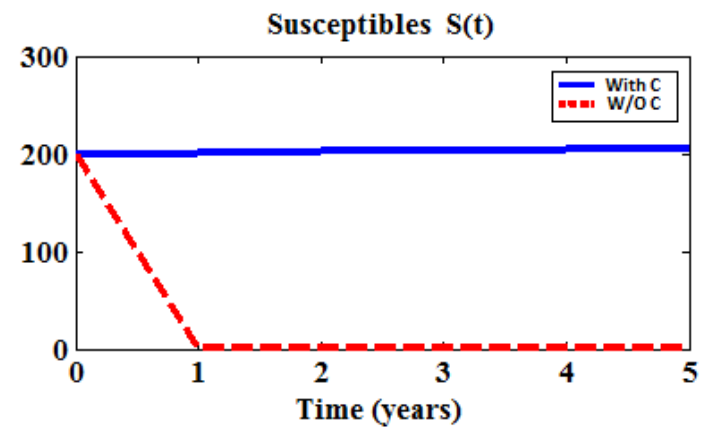

Function S with and without control

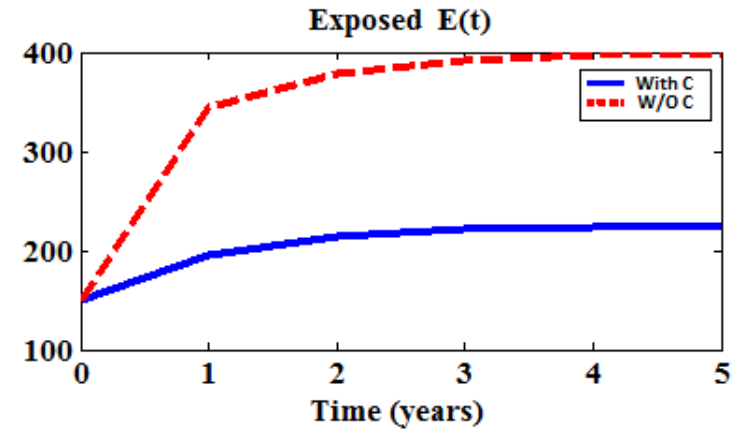

Function E with and without control

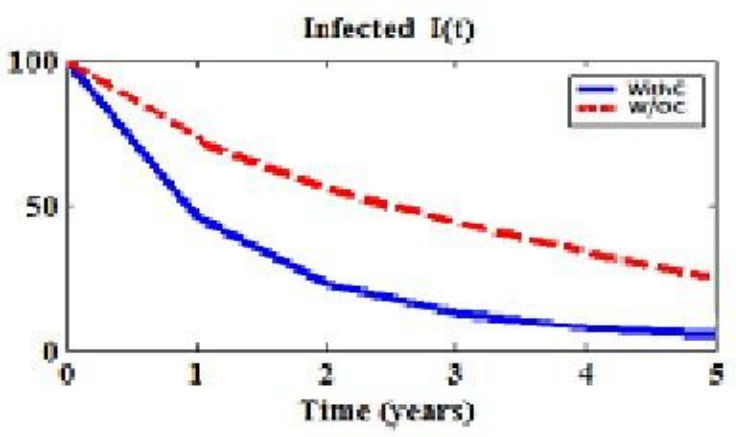

Function I with and without control

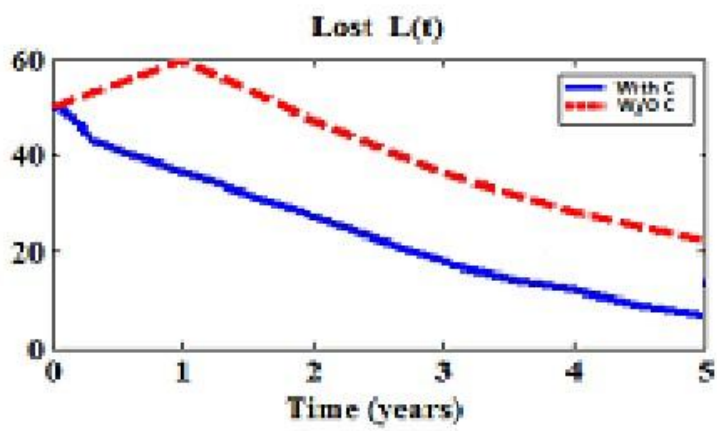

Function L with and without control

Volume 5 Issue 7, July 2016 www.ijsr.net 


\section{References}

[1] WHO. Fact sheet number 104. Technical report, World Health Organization, Geneva, Switzerland, 2012.

[2] Yves Emvudu, Rams'es Demasse, and Dany Djeudeu "Optimal Control of the Lost to Follow Up in a TuberculosisModel" Hindawi Publishing Corporation, Computational and Mathematical Methods in Medicine, Volume 2011.

[3] 12.L. S. Pontryagin, V. G. Boltyanskii, R. V. Gamkrelidze, and E. F. Mis- chenko, The Mathematical Theory of Optimal Process, John Wiley \& Sons, New York, NY, USA, 1992.

[4] W. H. Fleming, R. W. Rishel, Deterministic and Stochastic Optimal Control, Springer Verlag, New York, 1975.

[5] A. B. Gumel, P. N. Shivakumar, and B. M. Sahai, A mathematical model for the dynamics of HIV-1 during the typical course of infection, Third world congress of nonlinear analysts, (2001).

[6] J. Karrakchou, M. Rachik, and S. Gourari, Optimal control and Infectiology: Application to an HIV/AIDS Model, Applied Mathematics and Computation, (2006).

[7] National Institute of Statistics: Evolution des Systemes Statistiques Na- tionaux, Cameroun, 2007.

[8] National Committee of Figth Against Tuberculosis:Guide de Personel de laSanté, Cameroun, 2008. 